\title{
Residual stress states in cementite and ferrite in a combined cold drawing process of AISI 1045 steel using neutron diffraction and synchrotron radiation
}

\author{
Rafael Menezes Nunes ${ }^{1 *}$ (1) \\ Alexandre da Silva Rocha ${ }^{1}$ \\ Thomas Georg Karl Hirsch ${ }^{2}$
}

\begin{abstract}
The evaluation and control of residual stress states in manufacturing processes such as cold drawing can be difficult, especially in multi-phase materials. Diffraction methods are ideal for characterizing residual stresses in individual phases provided these phases scatter neutrons or X-rays well enough to obtain a good signal. Residual stresses determination problems in drawn components have been reported. Main constraints are measurements in the primary ferrite phase only. The presence of cementite in carbon steel is often neglected. A problem that has not yet been extensively investigated is how residual stresses in the ferrite and cementite phases develop in subsequent steps of material processing such as cold drawing. In this work a combined straightening and bar drawing process of AISI 1045 round bars from coils of a hot-rolled material was investigated. A careful characterization of the material, including residual stress states in the ferrite $(\alpha-\mathrm{Fe})$ and cementite $\left(\mathrm{Fe}_{3} \mathrm{C}\right)$ phases, using neutron diffraction and synchrotron diffraction was performed for each of the different manufacturing steps. The drawing and polishing and straightening (P.S.) parameters by crossed rolls were changed to evaluate their influence on the $\alpha-\mathrm{Fe}$ and $\mathrm{Fe}_{3} \mathrm{C}$ residual stress distributions. After the drawing process, residual stresses in the cementite phase are highly tensile, as already reported, however it can be shown that after polishing and straightening steps residual stresses in the cementite phase decrease and residual stress distributions also depend on the tool angle used.
\end{abstract}

Keywords: Combined cold drawing; Residual stress; Neutron diffraction; Synchrotron diffraction; Residual stresses; Cementite.

\section{Introduction}

The wire cold drawing processes can be defined as a manufacturing process in which a wire (or wire rod) is pulled through a die, thus causing a reduction in cross sectional area and an increase in length resulting from plastic deformation. This so called "combined cold drawing" involves several steps, starting from a wire rod coil manufactured by hot rolling which is pre-straightened to be then cold drawn, cut to a specific length and passing a combined polishing and straightening stage. A typical example of a "combined cold drawing" manufacturing process is given in [1].

The control of residual stress states in manufacturing processes such as cold drawing can be difficult, especially in multi-phase materials. Diffraction methods are ideal for characterizing residual stresses in individual phases provided these phases scatter neutrons or X-rays well enough to obtain a good signal $[2,3]$. Some authors have reported residual stresses determination problems in drawn components [4].

A not yet investigated problem is how residual stress states are changed in the ferrite and cementite phases in the subsequent steps of manufacturing. Past investigations concentrated only in fully pearlitic steels [3,5-7]. The main drawback of about residual stress states in cementite after drawing $[3,4]$ is the lack of knowledge from previous and subsequent steps of the cold drawing process: pre-straightening and polishing and straightening by crossed rolls respectively.

The main objective of this paper is an investigation concerning the phase specific residual stress distributions in ferrite $(\alpha-\mathrm{Fe})$ and cementite $\left(\mathrm{Fe}_{3} \mathrm{C}\right)$ before the drawing process, after drawing and in the subsequent steps of straightening and polishing. Energy dispersive modes in synchrotron radiation and neutron diffraction have been used for these experiments.

\section{Materials and methods}

The drawing experiments were carried out in an industrial manufacturing plant for the production of cold drawn bars. The received material condition were coils of hot rolled AISI 1045 steel. Figure 1 shows the manufacturing

\footnotetext{
${ }^{1}$ Laboratório de Transformação Mecânica, Universidade Federal do Rio Grande do Sul-UFRGS, Porto Alegre, RS, Brasil.

${ }^{2}$ Stiftung Institut für Werkstofftechnik, IWT, Universität Bremen, Bremen, Germany.

*Corresponding author: rafael.nunes@ufrgs.br
} 
steps of AISI 1045 cold-drawn bars. In the first step (step 1 in Figure 1) the rod is pulled from the coil by horizontally and vertically oriented straightening rolls, the so-called pre-straightening of the material. In the second step, the rod is shot blasted with steel shot (step 2 in Figure 1) to remove surface scale before entering the cold drawing tool (step 3 in Figure 1). In the 4th step the rod is cut to obtain bars of $6 \mathrm{~m}$ length. In the last step of the process, a polishing and straightening (P.S.) process is responsible to ensure the straightness required by industrial standards. In a cross-roll straightener, the rolls are set at angle $\delta$ with the axis of the bar. When a bar passes between the rolls the rotation of the rolls causes the rotation of the bar on its own axis as it progresses forward to the end of the process. The angle $\delta$ between the rolls was variable, and for this work, 16 and $18^{\circ}$ were used.

AISI 1045 (EN C45) wire rod with $21.46 \mathrm{~mm}$ diameter has been drawn to bars of $20.25 \mathrm{~mm}$ of diameter with a semi-die angle of 7.5 and $10^{\circ}$ respectively. Samples of 1000 $\mathrm{mm}$ were taken out of the process line and analyzed. The peripheral angular locations around the bars were used as a reference for all subsequent analyses. The " 0 " orientation is a horizontal line on the upper most position of the rods as they pass through the machinery. By marking this " 0 " " location the angular peripheral positions on the samples surface are defined relative to the machinery. This reference system is shown in Figure 2. This reference was important to correlate residual stresses with applied stresses during the process, due to differences of residual stress distributions as a consequence of bending moments applied in the process [1].

The preparation of samples for SEM images and for any further metallographic inspection followed standard procedures. Longitudinal cross sections were prepared by cutting samples of $10 \mathrm{~mm}$ in thickness at $15 \mathrm{~mm}$ distance from one end of the bars. These cut surfaces were manually polished successively with $220,400,600,1000$, and 1200 grid. With the use of diamond polishing fluids with a mean grain size of $1 \mu \mathrm{m}$ finally the true surface free of deformation, scratches, pull-outs, without introduction of foreign elements, without smearing and rounded edges as well as without any thermal damage was available to the examination [8].

\subsection{Details of the energy dispersive analysis with synchrotron radiation}

These measurements were carried out at the EDDI beam-line at BESSY (Berlin, Germany). The used set-up and more experimental details as well as the calculation of residual stresses can be found in [9]. Seen from the beamline perspective, the wiggler source has an effective size of about $12 \mathrm{~mm}$ in the horizontal (storage ring) plane and about $20 \mathrm{~mm}$ in the vertical plane which finally results in

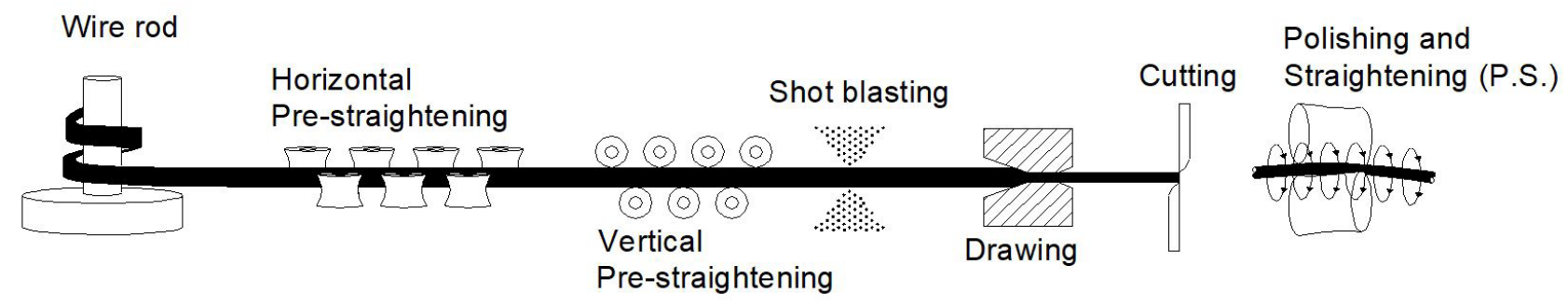

Figure 1. Main steps of investigated combined cold drawing manufacturing route.

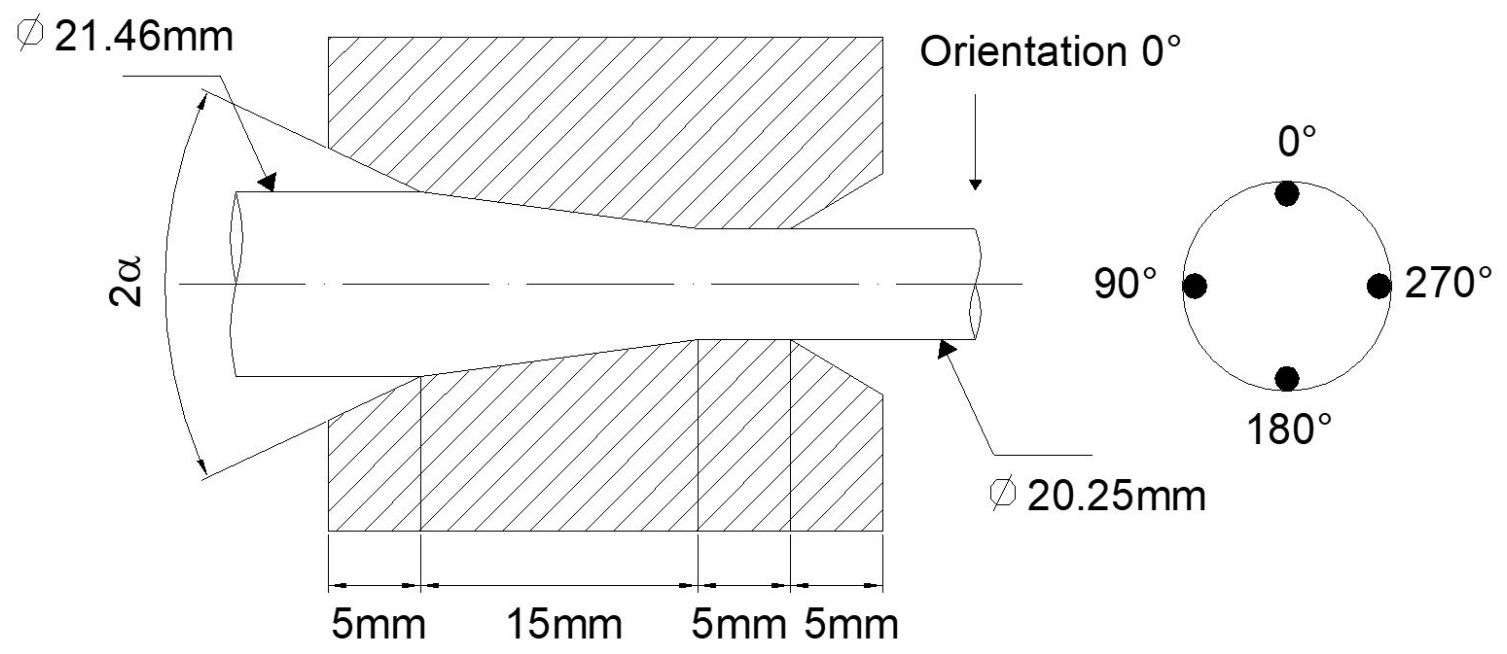

Figure 2. Schematic view of the drawing tool and orientation system. 
a homogeneous beam size of $4 \times 4 \mathrm{~mm} 2$. The maximum usable energy in the described energy dispersive diffraction experiments is around $80 \mathrm{keV}$ of the white synchrotron beam as provided by the wiggler. The slit system on the primary beam side was closed to a beam size of $125 \mu \mathrm{m}$ (axial) to $130 \mu \mathrm{m}$ (vertical) for the experiments. The diffractometer is equipped with a 5 -axes sample positioning unit and a detector arm with an optical bench for the slit systems of the diffracted beam. The diffracted beam is reduced to a size of $80 \mu \mathrm{m}$ in square. Low incidence angles of $2 \Theta=8^{\circ}$ are used. In the chosen configuration, the volume element of 125 to $130 \mu \mathrm{m}$ penetrates continuously into the sample by moving the sample up into the beam path (z-coordinate) [9]. Surface values of residual stresses were determined in axial and hoop direction (perpendicular and parallel to the beam path) with 50 pct. of this volume element penetrating into the surface. Further distances from surface were analyzed with the centre of the volume element penetrating at 150 $\mu \mathrm{m}$ surface distance and at $300,450,600,750 \mu \mathrm{m}$ up to $1600 \mu \mathrm{m}$ respectively. The diffraction spectra were recorded in the symmetrical $\psi$-mode after stepwise sample tilts at $\psi=0,18.43,26.57,33.21,39.23,45.00,50.77,56.79$, $63.43,71.57$ and $80.00^{\circ}$ for surface measurements and at $\psi=0,26.57,39.23,50.77$ and $63,43^{\circ}$ for measurements at increased surface distance. Diffraction lines of $\{110\}$, $\{200\},\{211\},\{220\}$ and $\{310\}$ lattice planes of the $\alpha$-iron were used for residual stress calculation in near surface layers (energies between 40 and $80 \mathrm{keV}$, whereas $\{211\}$, $\{220\},\{310\}$ and $\{222\}$ lines were analyzed at higher surface distances of the volume element (energies between 75 and $110 \mathrm{keV}$ ). With the $\psi$-tilts and $\mathrm{d} 0, \sin 2 \psi$ plots can be obtained for each reflection. As residual stresses within the different information depth of the different energies are almost constant, only mean values of residual stresses were calculated with the different lattice planes. In a similar way residual stresses in the cementite were determined on $\{121\} /\{210\}$-planes. Energy correction of measurements was made by comparison of ideal and measured energies for the different lattice planes of a certified Gold standard powder [9].

From the measured d-value, $\sigma 33$ was calculated assuming a biaxial stress state with equal stresses and a surface parallel state of residual stresses. The elastic constants used were $1 / 2 \mathrm{~s}^{2}$ equal to $5.73 * 10-6 \mathrm{~mm}^{2} / \mathrm{MPa}$ and $-\mathrm{s} 1$ equal to $1.24 * 10^{-6} \mathrm{~mm}^{2} / \mathrm{MPa}$, the $\mathrm{d}_{0}\{211\}$ is taken from the $\mathrm{a}_{0}$ value of ferrite with $0.28664 \mathrm{~nm}\left(\mathrm{~d}_{0}=0.11702 \mathrm{~nm}\right)$ [10]. The $\mathrm{d}_{0}$ value of the $\{121\} /\{210\}$ lattice planes of the cementite is calculated from the lattice parameters for cementite as given in [11] $\left(\mathrm{a}_{0}, \mathrm{~b}_{0}\right.$ and $\mathrm{c}_{0}$ values, where $\mathrm{a}_{0}=0.45246 \mathrm{~nm}$, $\mathrm{b}_{0}=0.50884 \mathrm{~nm}$ and $\left.\mathrm{c}_{0}=0.67423 \mathrm{~nm}\right)$. Elastic constants of ferrite have been used for the cementite as well as obviously a scatter band of elastic constants exists due to the different methods use for their determination and due to different modifications of cementite in steels.

The material used, a 1045 steel, contains $6.7 \mathrm{Vol} \%$ of cementite $\left(\mathrm{Fe}_{3} \mathrm{C}\right)$. Any neutron diffraction or X-ray diffraction analysis firstly will determine phase stresses in ferrite only. Literature results of residual stresses in cementite however point to very high tensile residual stresses in axial direction with values of more than $2000 \mathrm{MPa}$ [3-6]. Hoop and radial direction give high compressive residual stresses in the cementite (-1500 MPa) and consequently corrections must be made in the range of about $150 \mathrm{MPa}$ tensile residual stresses for the axial direction to about -100 MPa in radial and hoop direction. With the synchrotron radiation data of [4] at least an estimate can be made to fulfill axial and hoop symmetry of forces. The data of [4] was used only with one half of the bars data those with higher intensity and assumed that the distribution of residual stresses is symmetric for all residual stress components. After normalization of radial distances from the centre of the bar all experimental data was fitted by polynomials. The centre of the bar is defined at position " 0 " and -1 and +1 are at the upper and lower surfaces of the cylindrical bar if a radial cross section is seen.

The mean values of measured residual stresses are phase stresses ( $\sigma 11-\sigma 33)$. Macro and micro residual stresses are calculated from the following set of equations [5], with $\alpha-\mathrm{Fe}$ and $\mathrm{Fe}_{3} \mathrm{C}$ measured phase stresses, $\sigma \mathrm{I}$ the macro residual stresses and $\sigma$ II the micro residual stresses $\alpha-\mathrm{Fe}$ and $\sigma \mathrm{Fe}_{3} \mathrm{C}$ are axial stresses $\left(\sigma_{11}-\sigma_{33}\right)$.

\subsection{Details of the neutron diffraction analysis}

The neutron diffraction residual stress measurements were performed at the Helmholtz Zentrum Berlin, in Germany on beam line E3 of the BER II reactor. At the primary beam path a segmented elastically bent Silicon monochromator is installed giving a high neutron flux. The diffracted beam is recorded with a $3 \mathrm{He}$ Position Sensitive Detector of $300 \mathrm{~mm} \times 300 \mathrm{~mm}$ size using $256 \times 256$ channels. Finally, a goniometer with an automatic xyz-translation table is used. The distance between the diffractometer center and the detector was $1.3 \mathrm{~m}$. Details about the instrument can be found in [12].

In the incident beam, a mask with a cross section of $2 \times 2 \mathrm{~mm}$ was used. The aperture at the secondary side was accordingly $2 \mathrm{~mm}$ in width with no height limitation. As the neutron beam has a small divergence, the use of a mask at the primary side and the aperture in the diffracted beam allows selecting a diffracting volume quite precisely. The scattering vector is perpendicular to the measured $\{\mathrm{hkl}\}$ planes. Exclusively the $\{211\}$ diffraction line of $(\alpha-\mathrm{Fe})$ was selected for the measurements.

The wavelength for the experiments was 0.1486 $\mathrm{nm}$ and the diffraction line position was around $78.8^{\circ}$ in 2Theta. Volume elements in the diffractometer plane then have a rhombohedral shape. The measurements were carried out in the central plane of the bars at $100 \mathrm{~mm}$ distance from one end along a radius line, starting from the $0^{\circ}$ position up to $180^{\circ}$ as shown in Figure 2 and Figure 3.

The coordinate system of the measurements was placed at the central plane and in the center line of the sample. 
Accordingly volume elements were placed at positions $-10 \mathrm{~mm}$, up to $+10 \mathrm{~mm}$, with $1 \mathrm{~mm}$ steps. In summary residual stresses were determined for 20 different positions through the sample's cross section. The $0^{\circ}$ position (see Figure 2) of the bars as marked from the manufacturing process was always set to position $+10 \mathrm{~mm}$. It should be also noted that gauge volumes at position $10 \mathrm{~mm}$ and $9 \mathrm{~mm}$ positions were only partially immersed into the material, and deviations of line positions are to be expected with the use of plane apertures the so called surface effect $[13,14]$. The set-up of the instrument however minimized these effects $[15,16]$. The 2-dimensional data of the image plate detector are integrated and the obtained diffraction lines are fitted by a Gaussian after background subtraction. The strains are calculated with equation 6 from positions of diffraction lines corresponding to the $\{\mathrm{hkl}\}$ plane of the measured phase giving lattice spacing $d\{h k l\}$ through the Bragg's law, and the stress free lattice spacing $d_{0}$ [12]. Consequently neutron diffraction or $\mathrm{X}$-Ray diffraction analysis will be used to determine phase stresses in ferrite only.

\section{Results and discussion}

Firstly results of the Synchrotron radiation analysis will be summarized in the form of 2 tables. On the basis of these data recalculation of results from neutron diffraction, recalculated distributions of macro residual stresses and micro residual stresses in phases ferrite and cementite will be presented at the end of the results chapter.

Table 1 gives mean values of measurements from all accessible diffraction lines ( 5 different lattice planes) of the ferrite phase. The volume element in Synchrotron radiation measurements firstly penetrated the surface to $50 \%$ in these experiments. The cementite diffraction line intensities even with high counting times of 800 seconds were small. Only one or two cementite diffraction could be measured with sufficient line intensity and free from overlapping with diffraction lines from the ferrite. To overcome the scatter in the diffraction line positions in this case mean values of several measurements were used for the comparison between different manufacturing variants.

As can be seen from Table 1 phase stresses after the pre-straightening process before drawing, which is necessary to straighten the coiled wire, are compressive in the ferrite phase (-148 MPa) and are tensile in the cementite (339MPa).
Taking into account scatter from the weak diffraction line intensities of cementite, there is no doubt that after drawing tensile residual stresses are present in the ferrite phase for the analyzed AISI 1045 material as already indicated for an AISI 1080 material [4,5]. Extremely high values of more than $2000 \mathrm{MPa}$ are observed in the cementite phase. The additional straightening and polishing process with small additional amounts of plastic deformation then is responsible for another change in sign. Residual stresses in the ferrite again are compressive with values of -390 and $-450 \mathrm{MPa}$. Obviously the scatter of results is responsible for the slightly negative value in the cementite after the parameter combination drawn $20^{\circ}$ and P.S. $16^{\circ}$. The other parameter variations in Table 1 give tensile phase stresses in cementite of 370 and $300 \mathrm{MPa}$. Table 1 additionally gives information about the lattice parameter in the strain free direction $\sin ^{2} \psi^{*}$. These values can be used for an estimate of $\sigma_{33}$ [2]. Even with the powerful synchrotron radiation some scatter in the determination of energy position of diffraction lines cannot be excluded. As any information about $\sigma_{33}$ is difficult to obtain mean values of all lattice parameters at $\sin ^{2} \psi^{*}$ have been calculated to a value of $0,11705 \mathrm{~nm}$ plus minus 0,000022 nm. Assuming small values of $\sigma 33$ [2] a value of $\sigma_{33}$ can be calculated to be $+42 \mathrm{MPa}$ from the mean values of $0,11705 \mathrm{~nm}$ and the standard deviation of $2,2^{*} 10^{-5} \mathrm{~nm}$. This value should now be added to the phases stresses of ferrite in Table 1 and will shift all compressive phase stresses to more negative values and reduce the tensile residual stresses after the drawing process. This estimate for the $\sigma_{33}$ component of residual stresses in the cementite is hardly possible, because scatter of energy positions is far higher due to the small line intensities even for near surface volume elements. The following example will demonstrate the difficulties. As can be seen from Table 1 differences between highest and lowest strain free lattice parameters of cementite are 40 times higher compared to the values given for the strain free direction of the ferrite. On the other side the phase content of the cementite phase is only $6.7 \mathrm{Vol} \%$. As demonstrated for the ferrite phase it would be assumed now that there is only a small contribution form $\sigma_{33}$ to the residual stress values in cementite as it would lead to unreasonable high values of $\sigma_{33}$ calculated from the above mentioned differences of cementite lattice distances in the strain free direction.

In engineering, macro residual stresses in the beginning are these stresses to understand effects of residual stresses in

Table 1. Mean values of axial residual stresses in cementite and ferrite as well as measured $\mathrm{d}$ values in the strain free direction (drawing angles 20 and $15^{\circ}$, straightening and polishing angles 16 and $18^{\circ}$ ), $0^{\circ}$ position.

\begin{tabular}{|c|c|c|c|c|c|c|}
\hline & Straightened & Drawn $20^{\circ}$ & Drawn $15^{\circ}$ & $\begin{array}{c}\text { Drawn } 20^{\circ} / \text { P.S. } \\
16^{\circ}\end{array}$ & $\begin{array}{c}\text { Drawn } 20^{\circ} / \text { P.S. } \\
18^{\circ} \\
\end{array}$ & $\begin{array}{c}\text { Drawn } 15^{\circ} / \text { P.S. } \\
18^{\circ} \\
\end{array}$ \\
\hline Mean RS in $\alpha-\mathrm{Fe}[\mathrm{MPa}]$ & -148 & 196 & 249 & -391 & -396 & -449 \\
\hline Mean $\mathrm{RS}$ in $\mathrm{Fe}_{3} \mathrm{C}[\mathrm{MPa}]$ & 339 & 2621 & 2176 & -56 & 371 & 297 \\
\hline $\mathrm{d}\left(\sin ^{2} \psi^{*}\right) \alpha-\mathrm{Fe}\{211\}[\mathrm{nm}]$ & 0.11704 & 0.11705 & 0.11710 & 0.11707 & 0.11709 & 0.11699 \\
\hline $\mathrm{d}\left(\sin ^{2} \psi^{*}\right) \mathrm{Fe}_{3} \mathrm{C}\{121\}[\mathrm{nm}]$ & 0.23855 & 0.23845 & 0.23897 & 0.23841 & 0.23829 & 0.23827 \\
\hline
\end{tabular}


mechanical components. With the phase content of $6.7 \mathrm{Vol}-\%$ of cementite and macro residual stresses are calculated and summarized in Table 2. The micro-residual stresses in the two phases ferrite and cementite were determined for the small surface volume element and are presented in Table 2. Macro residual stresses are the result of a weighted volume average of micro residual stress states in both phases. As the ferrite volume fraction is higher, it will dominate residual stress states. The cementite shows very high tensile stresses which influence the final macro residual stress state and cannot be neglected. After pre-straightening macro residual stresses are compressive (-166 MPa) at the measured position of $0^{\circ}$ (see Figure 2). From X-Ray diffraction analysis of straightened bars ahead of the drawing it is already known that phase stresses in ferrite vary in axial direction as well as in circumferential direction due to the horizontal and vertical straightening [17]. After the calculation micro residual stresses in ferrite values of $-63 \mathrm{MPa}$ are present and those of $+873 \mathrm{MPa}$ in the cementite.

Residual micro stresses should be balanced in the two phases and a recalculation of the data should give values close to zero, as it is actually the case for $-63 \mathrm{MPa}$ and $870 \mathrm{MPa}$. After the drawing process tensile macroresidual stresses of $298 \mathrm{MPa}$ for the drawing angle of $20^{\circ}$ were found and $33 \mathrm{MPa}$ for the angle of $15^{\circ}$ respectively and the difference between the two drawing angles is obvious. Due to the plastic deformation in drawing micro residual stresses in the ferrite show increasing compression (-209 MPa and $-118 \mathrm{MPa}$ respectively). Micro residual stresses in the cementite remain high with values above $2500 \mathrm{MPa}[2,4,5]$. The superimposition of the final polishing and straightening to the drawn state lead to compressive values of the macro residual stresses. After the straightening and polishing process for all parameter variations compressive macro residual stresses between -230 MPa and -550 MPa are calculated, almost independent of the analyzed parameter variations. Micro-residual stresses in ferrite as well are almost independent of the process parameters with values between - $80 \mathrm{MPa}$ and -132 MPa. Micro residual stresses in the cementite remain high tensile as can be visualized in Table 2 (1113 MPa to $1844 \mathrm{MPa}$ ).

Figure 4 now shows the micro $\alpha$-Fe residual stress distributions for the drawing process with a $20^{\circ}$ tool angle as measured by neutron diffraction. Residual stresses in longitudinal and hoop direction show tensile stresses of $300 \mathrm{MPa}$ at the $0^{\circ}$ position. These values decrease continuously to the center of the bar, where longitudinal stresses are $-500 \mathrm{MPa}$ and hoop stresses -100 MP respectively. It should be noticed that for plotting a residual stress distribution against radial distances stress equilibrium cannot be observed. For the following pictures distribution related to normalized area dimensions therefore are displayed. With some deviation at the orientation of $-180^{\circ}$ the distribution of residual stresses along one cross section of the bar is symmetric. These differences are due the previous residual stresses distributions after pre-straightening. After drawing process a total residual stresses redistribution occurs, but cannot totally erase effects of pre straightening [1]. Figure 5 shows the micro $\alpha$-Fe residual stress states after the P.S.

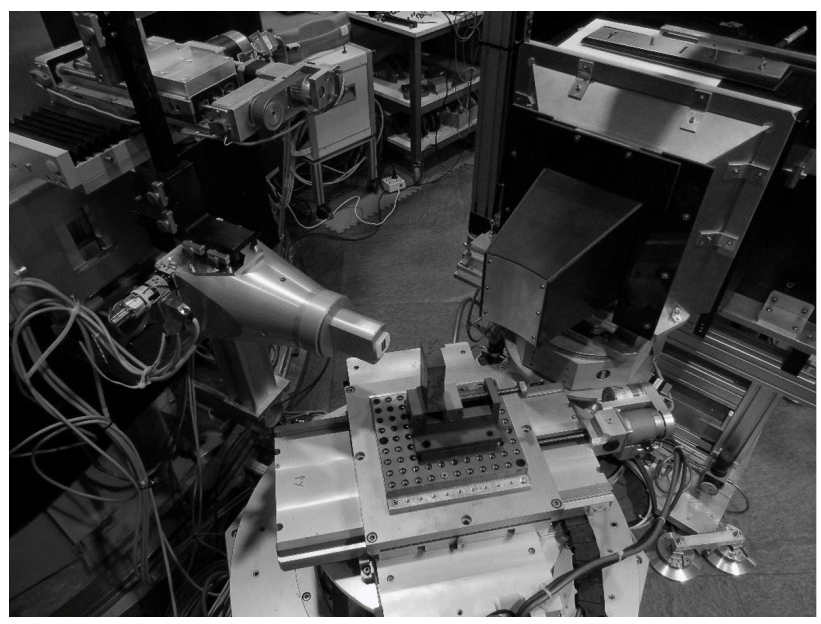

Figure 3. A Schematic sketch of the instrument with sample, incident beam aperture, diffracted beam mask.

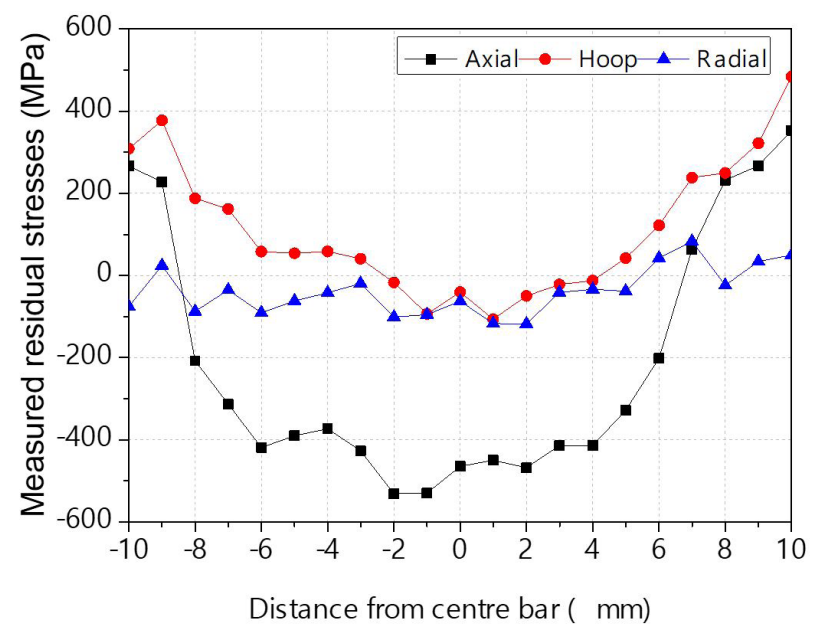

Figure 4. Micro $\alpha-$ Fe residual stress distributions after drawing with $20^{\circ}$ angle, cross section sample $0^{\circ}-180^{\circ}$ (Neutron diffraction as measured results).

Table 2. Evaluation of axial residual macro stresses, of axial micro stresses in ferrite and cementite

\begin{tabular}{|c|c|c|c|c|c|c|}
\hline & Straightened & Drawn $2^{\circ}$ & Drawn $15^{\circ}$ & $\begin{array}{c}\text { Drawn } 20^{\circ} / \text { P.S. } \\
16^{\circ} \\
\end{array}$ & $\begin{array}{c}\text { Drawn } 20^{\circ} / \text { P.S. } \\
18^{\circ} \\
\end{array}$ & $\begin{array}{c}\text { Drawn } 15^{\circ} / \text { P.S. } \\
18^{\circ} \\
\end{array}$ \\
\hline Axial macro RS [MPa] & -166 & 298 & 33 & -502 & -553 & -227 \\
\hline Axial micro RS $\alpha-\mathrm{Fe}[\mathrm{MPa}]$ & -63 & -209 & -118 & -80 & -132 & -109 \\
\hline Axial micro $\mathrm{RS} \mathrm{Fe}_{3} \mathrm{C}[\mathrm{MPa}]$ & 873 & 2906 & 2636 & 1113 & 1844 & 1490 \\
\hline
\end{tabular}


step with a $16^{\circ}$ tool angle in a previous $20^{\circ}$ drawn sample. longitudinal and hoop macro residual stresses distributions have compressive behavior in distances nearby surface and tensile residual stress close to the centerline for hoop and radial directions, in another way, longitudinal residual stress shows a compressive behavior near centerline of the sample. As observed in Figure 4, for drawing $20^{\circ}$ sample, the residual stresses also presents heterogeneities comparing symmetrical distances from the centerline of the sample.

Difficulties from the general problem with the $d_{0}$ value of Neutron diffraction experiments were overcome with the following procedure. The $\mathrm{d}_{0}$ value as a first estimate was calculated by a mean value of all neutron diffraction measurements for one production parameter. The $\mathrm{d}_{0}$ value then was optimized with a least squares method to gain axial and hoop force equilibrium. Measured residual stresses were plotted against $r_{2}$ for axial direction and against $r$ for hoop direction and $\mathrm{d}_{0}$ iteratively varied to reach axial and hoop force balance.

With these results a calculation of macro and micro residual stresses is possible for a surface volume element as mentioned for the synchrotron radiation data. Through thickness data can be determined with the data in Figures 4 and 5 and the synchrotron radiation data of [4,5]. Only few results are available about residual stresses in cementite, and for a drawing process they point to very high tensile residual stresses in axial direction with values of more than $2000 \mathrm{MPa}$ [3-5]. Hoop and radial direction counterbalance these tensile residual stresses with values of up to -1500 MPa. Data of $[4,5]$ were normalized by the bar diameter and fitted by a polynomial. These polynomials are used to calculate through thickness distribution of phases stresses in cementite with a starting value from values measured by the Synchrotron radiation data in Table 1 and 2.

After the drawing process, macro residual stress distribution through the cross section of a central plane is presented in Figure 6 for drawing angles of $15^{\circ}$. As expected high tensile residual stresses of up to $350 \mathrm{MPa}$ for the axial and hoop direction were observed in surface layers and compressive residual stresses of $-550 \mathrm{MPa}$ are present in the center of the bars for the balance of forces. The radial residual stresses in near surface layers are zero and show compressive values of up to -200 MPa in the center of the bar.

A macro residual stress distribution through the cross section of a central plane for drawing angle of $20^{\circ}$ is presented in Figure 7. A high tensile residual stresses of up to $450 \mathrm{MPa}$ for the axial and hoop direction were observed in surface layers and compressive residual stresses of $-450 \mathrm{MPa}$ are present in the center of the bars for the balance of forces. The comparison between 15 and $20^{\circ}$ shows some differences in the near surface and center residual stress values, the $15^{\circ}$ bar show a decrease value in tensile residual stress values of about $100 \mathrm{MPa}$ in axial direction, the $20^{\circ}$ bar shows a decrease of compressive axial residual stress in the center of the bar. The radial residual stresses in near surface layers are zero and show compressive values of up to $-200 \mathrm{MPa}$ in

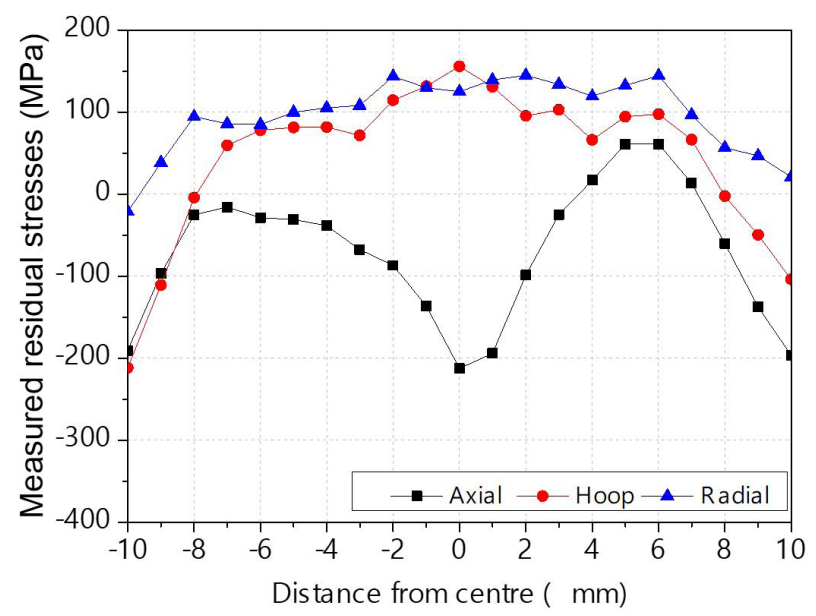

Figure 5. Micro $\alpha-\mathrm{Fe}$ residual stress distributions, as measured, after P.S. step with a $16^{\circ}$ tool angle in a previous $20^{\circ}$ drawn sample, cross section (Neutron diffraction as measured results).

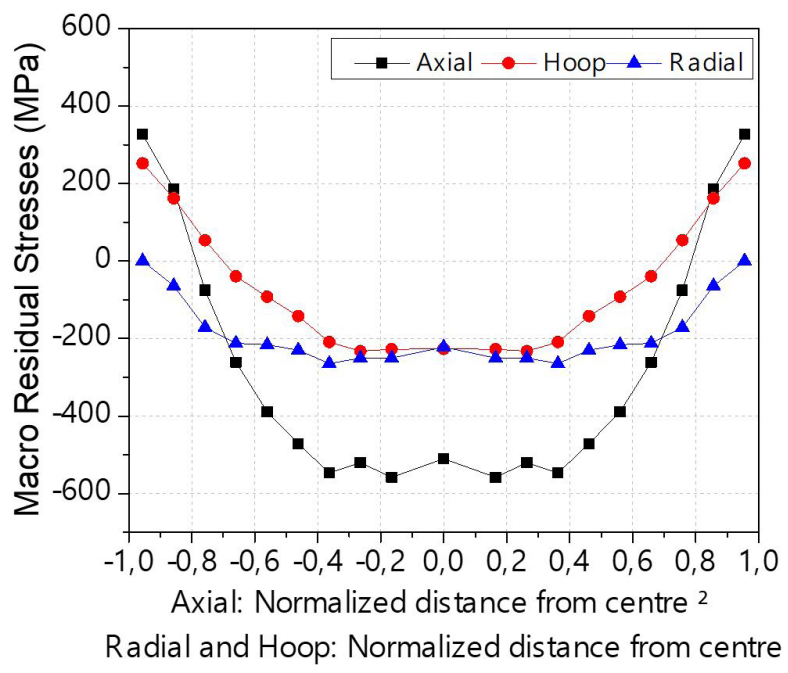

Figure 6. Macro residual stresses after drawn step with a $15^{\circ}$ tool angle, cross section.

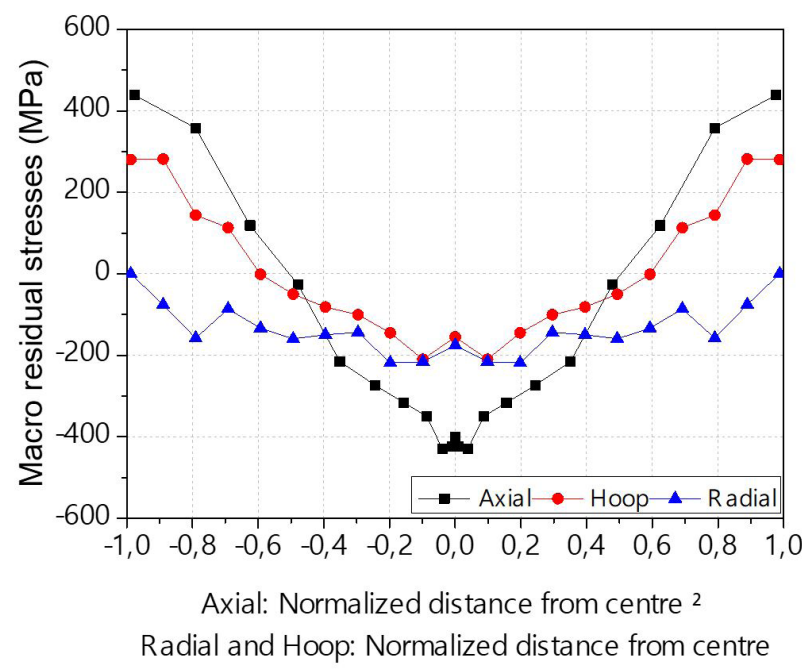

Figure 7. Macro residual stresses after drawn step with a $20^{\circ}$ tool angle, cross section. 
the center of the bar. However radial residual stresses are calculated after force equilibrium for the axial and hoop direction with the $d_{0}$ value then obtained. It is consequently the result of the force equilibrium calculation for the axial and hoop directions.

For the complete description of residual stress states in a total cross section, Figure 8 (P.S. $16^{\circ}$ - Drawn $20^{\circ}$ ) shows macro residual stresses plotted against normalized radial distances. As expected the polishing and straightening process changes the residual stress in the cross section completely. The high tensile residual stresses at the surface of drawn bars are shifted to compressive residual stresses and a re-distribution can be observed throughout the remaining cross section. Some tensile residual stresses however remain for the axial and hoop direction at $50 \mathrm{pct}$ of the radius. In the center of the bar axial residual stresses are still in compression while hoop residual stresses are in tension. Radial residual stresses after the calculation for force equilibrium can be found to be about $50 \mathrm{MPa}$ in tension which is in the order of precision to be reached by Neutron diffraction measurements.

The complete description of residual stresses states in a cross section Figure 9 (P.S. $18^{\circ}$ - drawn $20^{\circ}$ ) shows macro residual stresses plotted against normalized radial distances. In the surface, in axial and hoop directions, compressive residual stresses can be seen while in the radial direction residual stresses are around zero. In the same way for $16^{\circ}$ tensile residual stresses for $18^{\circ}$ remain for the axial direction at 60 pct of the radius, however this not occurs for hoop direction. In the center of the bar axial residual stresses are still in compression while the hoop and radial residual stresses are tensile.

The combined cold drawing process starts with uncoiling the wire rod and fed through a straightening unit, the first applied strains arise in the horizontal pre-straightening unit following the vertical straightening process. Therefore, this applied set of stresses in horizontal/vertical peripheral position

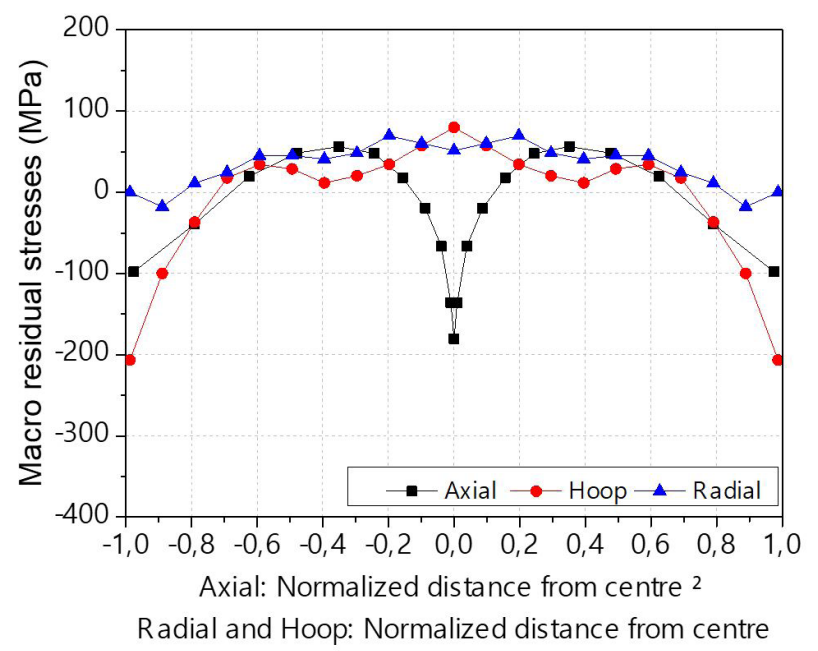

Figure 8. Macro residual stresses after P.S. step with a $16^{\circ}$ tool angle in a previous $20^{\circ}$ drawn sample, cross section. of wire generates a residual stress state which partially can be interpreted as a state after elastic plastic bending.

In the drawing process, as reported by $[2,4,5,18]$ the cold drawing process will induce a high defragmentation of cementite lamellae and It is well known that the cementite $\left(\mathrm{Fe}_{3} \mathrm{C}\right)$ phase in ferritic steels is subjected to large stresses during the cold drawing process. The most accepted explanation reported is that the $\mathrm{Fe}_{3} \mathrm{C}$ lamellae will fragment due to these stresses [19]. This work, concerning the cementite fragmentation, shows the same behavior reported in the state of the art, the mean values of macro $\mathrm{Fe}_{3} \mathrm{C}$ residual stresses in cold drawing were found to be 2176 and $2621 \mathrm{MPa}$ for 15 and $20^{\circ}$ cold drawing angles respectively. The comparison between ferrite and cementite hardness shows that cementite is a much harder than ferrite, as a consequence of this difference during wire drawing process there was a cementite fragmentation outstanding the difference responses of strains in cementite and ferrite, subsequently, high micro- $\mathrm{Fe}_{3} \mathrm{C}$ tensile residual stresses are generated $[2,20]$. As a consequence, the softer ferrite facilitates the plastic flow during the drawing process, in other hand, as a response of high hardness, the cementite plastic flow is delayed if there is any unknown cementite. It is possible that the high tensile stresses in cementite will be responsible for a localized fracture of some good oriented lamellae. Therefore, the stress in the cementite plates increase substantially, leading to a defragmentation fracture and high tensile stresses [2,11,19,21].

The Polishing and Straightening by crossed rolls is the last step of the process. After this step complete redistributions of residual stress occur in the bar profile, as shown in Figures 7 and 8 . In the P.S. process two kinds of plastic strains occur, the first is due to the concave roll, this roll generates a bending residual stress state in the bar. At the same time, the convex roll is responsible for a final polishing of the bar, and is responsible to a localized plastic deformation in the surface with a penetration of less than $1 \mathrm{pct}$, this plastic deformation

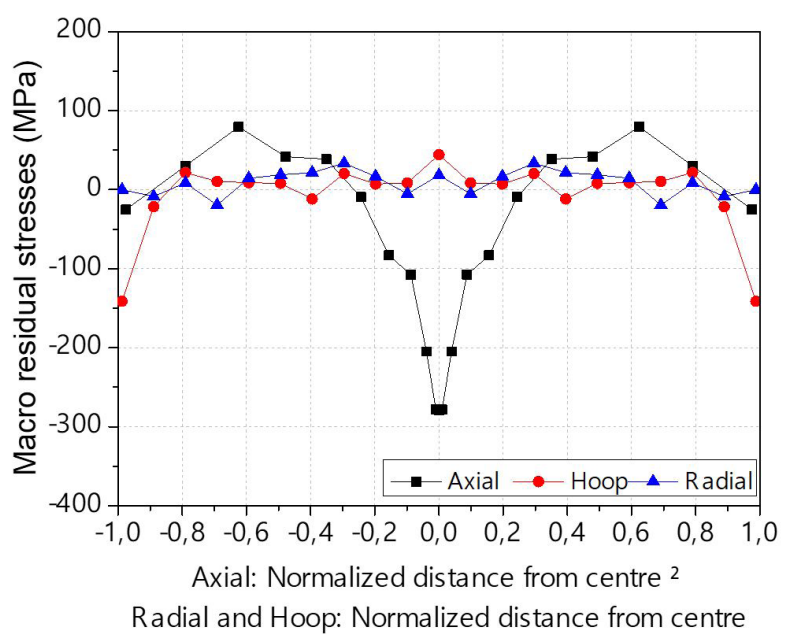

Figure 9. Macro residual stresses after P.S. step with an $18^{\circ}$ tool angle in a previous $20^{\circ}$ drawn sample, cross section. 
causes the surface elongation. The nature of residual stresses introduced by plastic deformation strongly depends upon the shape of the deformation zone [17,22], due to this, it is obvious that the residual stress nature and magnitude in P.S. process will be closely dependent on the convex roll.

The comparison between the three analyzed sets of P.S. parameters show that the crossed rolls angle affect the mean macro $\alpha-\mathrm{Fe}$ residual stress values. Mean values of $-391,-396$ and -449 MPa can be found in Table 1 for a set of drawing/P.S. parameters $20^{\circ} / 16^{\circ}, 20^{\circ} / 18^{\circ}$ and $15^{\circ} / 18^{\circ}$ respectively. After P.S. some influence of the drawing angle in the surface mean macro $\alpha-F e$ residual stresses values were found, the bars that were drawn with $15^{\circ}$ generates more compressive residual stresses in $\alpha-\mathrm{Fe}$. The generation and redistribution of residual stresses in crossrolls straightening occurs by the low penetration plastic deformation caused by convex roll with the sum of the plastic deformation generated by the concave roll due to the bent state of the bar [1]. The plastic deformation caused by convex roll generates a surface elongation, as a cold drawing process with a reduction of less than $1 \mathrm{pct}$, therefore a compressive residual stress behavior will be generated in the surface. According to the force equilibrium principle, tensile residual stresses will be generated in the center of this bar. For the mean $\mathrm{Fe}_{3} \mathrm{C}$ macro residual stresses in the surface, values of -56, 371 and $297 \mathrm{MPa}$ have been found in Table 1 for a set of drawing/P.S. parameters of $20 / 16^{\circ}$, $20 / 18^{\circ}$ and $15 / 18^{\circ}$ respectively. Therefore, the localized plastic deformation in the surface caused by the convex roll in the P.S. process generates an elongation stress in the surface, as a consequence, the $\mathrm{Fe}_{3} \mathrm{C}$ macro stress changed the behavior for a $16^{\circ}$ and will be less tensile for $18^{\circ}$ P.S. angle. In fact, some previous works have shown that the surface residual stresses will be more compressive in the surface using a P.S. angle of $16^{\circ}[1,17]$.

According to Porter et al. [18], fracture of pearlite is closely related to the modes of plastic deformation, and the main differences between coarse and fine pearlites can be attributed to the homogeneity of slip and the stability of microvoids. Thus in coarse pearlite cracks are initiated at relatively low applied strains either by the opening up and expansion of voids in intense shear bands (shear cracking) or by rupture of the ferrite parallel to the cementite lamellae $[18,19]$. In this way, the consecutive bending and unbending stress states generated in a set of horizontal/vertical straightening rolls generates, in fact, the first cementite lamellae defragmentation due to successive bending/unbending applied stress. Therefore, high tensile micro- $\mathrm{Fe}_{3} \mathrm{C}$ residual stresses are generated, due the plastic deformation, in all steps of the combined wire drawing process, and the magnitude of these generated is closed to the applied strains. As a consequence, macro residual stresses will be affected in certain way becoming more tensile.

\section{Conclusions}

For the first time in a combined cold drawing manufacturing process the $\mathrm{Fe}_{3} \mathrm{C}$ residual stresses were determined to clarify the behavior in manufacturing steps ahead and after a combined cold drawing process.

Starting from the results, there is an evidence that the first fragmentation of $\mathrm{Fe}_{3} \mathrm{C}$ occurs in the pre-straightening process, a mean residual stress value of $339 \mathrm{MPa}$ was found at the wire rod surface. The residual stress profile after pre-straightening process shows a typical bending stress state with compressive and tensile residual stress states depending on the side and position of analyzed samples. The comparison between $\mathrm{Fe}_{3} \mathrm{C}$ and $\alpha$-Fe mean values shows significant behavior differences with tensile and compressive states respectively.

In cold drawing process itself, the $\mathrm{Fe}_{3} \mathrm{C}$ presents high tensile residual stress values for AISI 1045 steel, as reported by literature to AISI 1080 steel, as well tensile macro residual stresses were found in $\alpha$-Fe.

Finally, the mean $\alpha-\mathrm{Fe}$ surface residual stresses mean values after P.S. presents compressive and the $\mathrm{Fe}_{3} \mathrm{C}$ mean values shows compressive or tensile values, and this behavior depends on the P.S. angle and the magnitude is connected with the drawing angle. The superimposition of the final polishing and straightening to the drawn state lead to compressive values of the macro residual stresses after P.S process.

Therefore the control of the process parameters is an important way to control the distributions and levels of residual stresses at the end of combined wire drawing process.

From the general view of the process, the micro residual stresses levels presents significant differences in $\alpha-\mathrm{Fe}_{2}$ and $\mathrm{Fe}_{3} \mathrm{C}$ in all steps of combined wire drawing process evaluated in this work. The residual stresses analysis shows that the micro $\mathrm{Fe}_{3} \mathrm{C}$ exerts some significant influence in Macro residual stresses distributions and cannot be neglected for this process.

\section{Acknowledgements}

This work was developed in the frame of the "BRAGECRIM" program (Brazilian German Cooperation Research Initiative in Manufacturing). The authors are deeply indebted to the DFG, CAPES, CNPq, and Finep for financial support and to HZB Berlin (neutron diffraction measurements) in special Dr. Robert Wimpory and HZB EDDI (Energy dispersive analysis of residual stresses with Synchrotron radiation) in special Prof. Dr. Christoph Genzel and Dr. Manuela Klaus. One Author, Thomas Hirsch, is deeply indented to the colleges from HZB Berlin for their intense and warm support. Preliminary cooperation also would not have been possible without support from the DAAD and CAPES. The neutron diffraction analysis has been supported by the European Commission under the 7th Framework Program through the Key Action: Strengthening the European Research Area, Research Infrastructures: Contract No. 226507 (NIMI3).. 


\section{References}

1 Rocha AS, Nunes RM, Hirsch T. Changes in the axial residual stresses in AISI 1045 steel bars resulting from a combined drawing process chain. Proceedings of the Institution of Mechanical Engineers Part B-Journal of Engineering Manufacture. 2012;226:459-465.

2 Hauk V, Behnken H. Structural and residual stress analysis by nondestructive methods: evaluation, application, assessment. Amsterdam: Elsevier; 1997.

3 VanAcker K, Root J, VanHoutte P, Aernoudt E. Neutron diffraction measurement of the residual stress in the cementite and ferrite phases of cold-drawn steel wires. Acta Materialia. 1996;44(10):4039-4049. http://dx.doi.org/10.1016/S13596454(96)00051-1.

4 Martinez-Perez ML, Mompean FJ, Ruiz-Hervias J, Borlado CR, Atienza JM, Garcia-Hernandez M, et al. Residual stress profiling in the ferrite and cementite phases of cold-drawn steel rods by synchrotron X-ray and neutron diffraction. Acta Materialia. 2004;52(18):5303-5313. http://dx.doi.org/10.1016/j.actamat.2004.07.036.

5 Martinez-Perez ML, Borlado CR, Mompean FJ, Garcia-Hernandez M, Gil-Sevillano J, Ruiz-Hervias J, et al. Measurement and modelling of residual stresses in straightened commercial eutectoid steel rods. Acta Materialia. 2005;53(16):4415-4425. http://dx.doi.org/10.1016/j.actamat.2005.05.039.

6 Atienza JM, Elices M. Influence of residual stresses in the tensile test of cold drawn wires. Materials and Structures. 2003;36(8):548-552. http://dx.doi.org/10.1007/BF02480832.

7 Caballero L, Atienza JM, Elices M. Thermo-mechanical treatment effects on stress relaxation and hydrogen embrittlement of cold-drawn eutectoid steels. Metals and Materials International. 2011;17(6):899-910. http://dx.doi. org/10.1007/s12540-011-6006-8.

8 Vander Voort GF. Metallography, principles and practice. Materials Park, Ohio: ASM International; 1999. 752 p.

9 Genzel C, Denks IA, Gibmeier J, Klaus M, Wagener G. The materials science synchrotron beamline EDDI for energy-dispersive diffraction analysis. Nuclear Instruments and Methods in Physics Research Section A: Accelerators, Spectrometers, Detectors and Associated Equipment. 2007;578(1):23-33. http://dx.doi.org/10.1016/j.nima.2007.05.209.

10 Genzel C, Stock C, Reimers W. Application of energy-dispersive diffraction to the analysis of multiaxial residual stress fields in the intermediate zone between surface and volume. Materials Science and Engineering: A. 2004;372:28-43.

11 Caballero FG, Garcia-Mateo C, de Andres CG. Dilatometric study of reaustenitisation of high silicon bainitic steels: decomposition of retained austenite. Materials Transactions. 2005;46(3):581-586. http://dx.doi.org/10.2320/ matertrans.46.581.

12 Poeste T, Wimpory RC, Schneider R. The new and upgraded neutron instruments for materials science at HMI - current activities in cooperation with industry. Materials Science Forum. 2006;524-525:223-228. http://dx.doi.org/10.4028/ www.scientific.net/MSF.524-525.223.

13 Fitzpatrick ME. Alain Lodini: analysis of residual stress by diffraction using neutron and synchrotron radiation. London: Taylor \& Francis; 2003. http://dx.doi.org/10.1201/9780203608999.

14 Gibmeier J, Kornmeier J, Hofmann M. Neutron Diffraction Stress Analysis of Near Surface Stress Gradients of Surface Treated Steel Samples. Advances in X-ray Analysis. 2009;52:279-286.

15 Webster GA, Wimpory RC. Development of procedures for the measurement of residual stress by neutron diffraction. Appl Phys a-Mater. 2002;74:S1227-S1229.

16 Wimpory RC, Ohms C, Hofmann M, Schneider R, Youtsos AG. Corrigendum to "Statistical analysis of residual stress determinations using neutron diffraction" [International Journal of Pressure Vessels and Piping 86(1) 48-62]. International Journal of Pressure Vessels and Piping. 2009;86(10):721-721. http://dx.doi.org/10.1016/j. ijpvp.2009.03.003.

17 Hirsch TGK, Rocha AS, Nunes RM. Distortion Analysis in the Manufacturing of Cold-Drawn and Induction-Hardened Components. Metallurgical and Materials Transactions A. 2013;v(n):1-11.

18 Porter DA, Easterling KE. Dynamic studies of the tensile deformation and fracture of pearlite. Scandinavian Journal of Metallurgy. 1978;7:55-56.

19 Miller LE, Smith GC. Tensile fractures in carbon steels. Journal of the Iron and Steel Institute. 1970;208:998-1005.

20 Li S, Yip TH, Ramanujan RV, Liang MH. Insitu TEM studies of the mechanisms of crack nucleation and propagation in fully lamellar microstructures. Materials Science and Technology. 2003;19(7):902-906. http://dx.doi. org/10.1179/026708303225004378.

21 Rosenfield AR, Hahn GT, Embury JD. Fracture of steels containing pearlite. Metallurgical and Materials Transactions. B, Process Metallurgy and Materials Processing Science. 1972;3(11):2797-2804. http://dx.doi.org/10.1007/ BF02652845.

22 Dastalukder NK, Singh AN. Mechanics of bar straightening, part 2: straightening in cross-roll straighteners. Journal of Engineering for Industry. 1991;113(2):228-232. http://dx.doi.org/10.1115/1.2899683.

Received: 17 Aug. 2020

Accepted: 6 Oct. 2020 